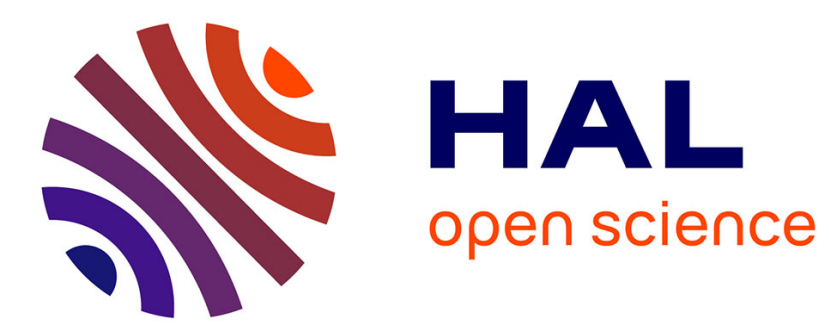

\title{
Microstructural characterization of shear band formation in Al-Li alloys
}

R. Chen, K. Vecchio

\section{To cite this version:}

R. Chen, K. Vecchio. Microstructural characterization of shear band formation in Al-Li alloys. Journal de Physique IV Proceedings, 1994, 04 (C8), pp.C8-459-C8-464. 10.1051/jp4:1994871 . jpa-00253432

\section{HAL Id: jpa-00253432 https://hal.science/jpa-00253432}

Submitted on 1 Jan 1994

HAL is a multi-disciplinary open access archive for the deposit and dissemination of scientific research documents, whether they are published or not. The documents may come from teaching and research institutions in France or abroad, or from public or private research centers.
L'archive ouverte pluridisciplinaire HAL, est destinée au dépôt et à la diffusion de documents scientifiques de niveau recherche, publiés ou non, émanant des établissements d'enseignement et de recherche français ou étrangers, des laboratoires publics ou privés. 


\title{
Microstructural characterization of shear band formation in Al-Li alloys
}

\author{
R.W. Chen and K.S. Vecchio \\ Dept. of Applied Mechanics and Engineering Sciences, University of CA, San Diego, LaJolla, CA 92093, \\ U.S.A.
}

\begin{abstract}
Resumé
Les alliages de Al-Li fournissent une opportunité unique pour l'étude de l'histoire thermique de la formation des bandes de cisaillement. Ceci ce fait en suivant la dissociation thermique de la phase précipétéc $\delta^{\prime}\left(\mathrm{Al}_{3} \mathrm{Li}\right)$ comme fontion de la concentration du $\mathrm{Li}$ et la température du solvus $\delta^{\prime}$. La température du solvus $\delta^{\prime}$ augmente avec l'augmentation de la concentration du Li. Donc, la dissolution de $\delta^{\prime}$ dans les bandes de cisaillement, en fonction de la concentration du Li, peux fournir une sonde de temperature interne pour étudier l'histoire thermique des bandes de cisaillement. Dans les tests expérimentaux qui ont été conduit, des bandes de cisaillement on été produites dans les échantillons déformés à des vitesses de $104 / \mathrm{s}$. Il à été trouvé que la dissolution est une fonction de la vitesse de déformation, du taux de déformation et de la concentration du $\mathrm{Li}$. Les résultats de ce travail sont utilsés comme moyen de differecier les deux théories prédominaantes pour la recristallisation dynamique: le modéle classique de nucléation et grocissement avec grand angles de joints de grains ou le modéle de coalescence des sous-grains.
\end{abstract}

\begin{abstract}
The Al-Li alloy system can provide a unique opportunity to study the thermal history of shearband formation by following the thermal dissolution of the precipitate phase $\delta^{\prime}\left(\mathrm{Al}_{3} \mathrm{Li}\right)$ as a function of $\mathrm{Li}$ concentration and $\delta^{\prime}$ solvus temperature. The metastable $\delta^{\prime}$ solvus increases in temperature with increasing Li concentration. As such, the dissolution of $\delta$ ' within the shear bands, as a function of $\mathrm{Li}$ alloy concentration, can provide an internal temperature probe to study the thermal history of the shear band. Experiments were conducted in which shear bands were produced in specimens at a strain rate of $104 / \mathrm{s}$. It was found that dissolution was a function of strain rate, strain, and Li concentration. The results of this work were used as a means of further differentiating between the two predominant theories on dynamic recrystallization: the classical nucleation and growth with high-angle grain-boundaries model or the subgrain-coalescence model.
\end{abstract}

\section{INTRODUCTION}

Shear-band formation under high-strain-rate conditions can be assumed to be adiabatic when the rate of deformation exceeds the material's ability to conduct away the heat generated by the deformation. The evolved heat during shear banding plays a significant role in the formation of the shear band due to the profound effect temperature has on the flow stress, hardening rates, and deformation mechanisms in metal alloys. Direct measurement of the temperature rise associated with shear banding is difficult due to: (a) the short time duration of the process under high strain rate conditions, and (b) the fact that shear bands form internally in the specimens, making surface measurements suspect. The Al-Li alloy system can provide a unique opportunity to study the thermal history of shear-band formation by following the 
thermal dissolution of the precipitate phase $\delta^{\prime}\left(\mathrm{Al}_{3} \mathrm{Li}\right)$ as a function of Li concentration and therefore $\delta^{\prime}$ solvus temperature. The Al-Li system was chosen primarily for the rather rapid precipitation and dissolution kinetics resulting from the high diffusivity of $\mathrm{Li}$ in the Al lattice. $\delta^{\prime}$ is a spherical, coherent and metastable precipitate which is the main strengthening phase in dilute $\mathrm{Al}-\mathrm{Li}$ alloys. Although $\delta^{\prime}$ is metastable, the location of the $\delta^{\prime}$ solvus in the Al-Li phase diagram has been well documented for dilute $\mathrm{Li}$ additions $(<5 \mathrm{wt} . \% \mathrm{Li})$ [e.g. 1]. The metastable $\delta^{\prime}$ solvus increases in temperature with increasing $\mathrm{Li}$ concentration. As such, the dissolution of $\delta^{\prime}$ within the shear bands, as a function of $\mathrm{Li}$ alloy concentration, can provide an internal temperature probe to study the thermal history of the shear band. For example, if the $\delta^{\prime}$ solvus temperature for a $2 \mathrm{wt} . \% \mathrm{Li}$ alloys is $235^{\circ} \mathrm{C}$, and $\delta^{\prime}$ is dissolved within the shear band during its formation, then it can be assumed that the temperature within the shear band exceeded $235^{\circ} \mathrm{C}$. When an alloy composition is found in which the $\delta^{\prime}$ is not dissolved during shear band formation, then a small window around the actual shear band temperature can be determined.

\section{EXPERIMENTAL TECHNIQUES}

Four different $\mathrm{Al}-\mathrm{Li}$ alloys were produced ranging in composition from approximately $2 \mathrm{wt} \% \mathrm{Li}$ to 4 wt.\% Li. Figure 1 shows the Al-Li phase diagram with the four Li compositions chosen and their corresponding solvus temperatures indicated. The heat treatment of each alloys was chosen to achieve the same size $\delta^{\prime}$ distributed throughout the matrix. Hat-shaped specimens, shown schematically in Figure 2 , were used to generate high strain, high-strain-rate deformation under controlled, prescribed conditions. The hat-shaped specimen was developed by Meyer and co-workers [2], and has a circular cross-section and a narrow overlapping region which concentrates the shear deformation. The displacement, $\delta$, illustrated in Figure 2 , is determined and controlled by a steel ring which limits the movement of the narrow end of the specimen. The specimen is dynamically compressed using a split Hopkinson bar, see Nemat-Nasser et. al. [3] for details, recovered and sectioned for analysis using both optical microscopy and transmission electron microscopy (TEM). The region of concentrated deformation is close to pure shear, and the shear stresses can be approximated based on the original dimensions of the overlap region and shear strains can be estimated by measuring the displacement, $\delta$, and determining the thickness of the shear region by optical microscopy.

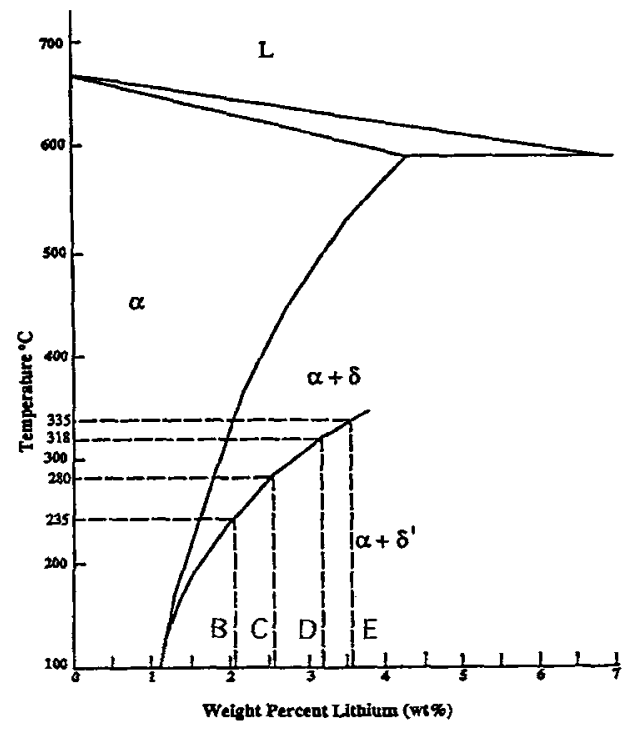

Figure 1. Al-Li phase diagram showing the four alloys $(B, C, D, E)$ along with their corresponding $\delta$ ' solvus temperatures. (a)

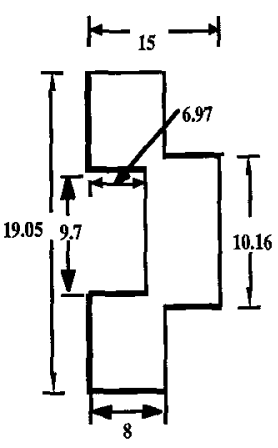

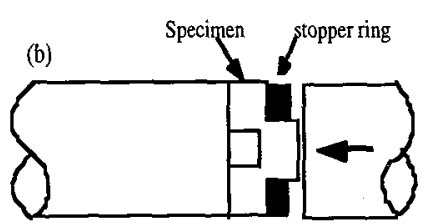

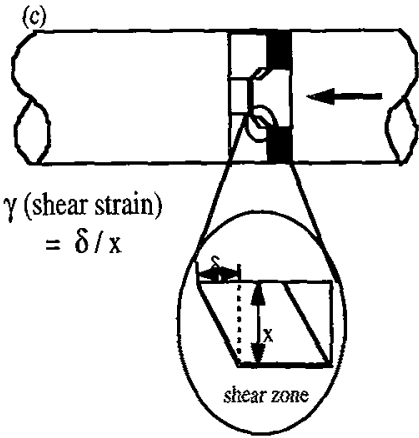

Figure 2. Schematic diagram of (a) the "hatshaped" specimen (dimensions in $\mathrm{mm}$ ) used to generate the high-strain-rate shear deformation, (b) before compression in Hopkinson bars, (c) after compression. 
At high strain rate, the formation of the shear band can be assumed to be adiabatic since the deformation occurred in a time frame similar to that required for cooling of the shear band region. A significant degree of heating occurs in the shear band as a result of the intense localized deformation. When this heating was sufficient to raise the temperature of the material above the $\delta$ ' solvus temperature of the particular alloy, dissolution of the $\delta^{\prime}$ was expected to occur, with its absense or presence within the shear band determined by the existence of superlattice reflections in microdiffraction patterns and/or dark-field imaging. Figure 3 contains $\delta$ ' superlattice dark-field TEM micrographs of each of the four Al-Li alloys showing the initial microstructures which consisted of $\sim 70 \mathrm{~nm}$. precipitates; the initial grain size for each alloy was approximately $300 \mu \mathrm{m}$.

\section{RESULTS AND DISCUSSION}

Figure 4(a) shows an optical microgragh of a macroscopic shear band in Alloy C (2.6 wt.\% Li); the width of the shear band is less than $100 \mu \mathrm{m}$. The macroscopic shear bands decreased in width with increasing $\mathrm{Li}$ concentration, and increased in width with increasing shear strain. When TEM was employed to examine the microstructure of the shear band regions, two types of shear bands were observed: (1) macroscopic shear bands similar to those shown in Figure 4, and (2) grain-scale shear bands similar to the one shown in Figure 6(a). Figure 4(b) shows a montage of TEM micrographs taken across a macroscopic shear band in Alloy E (3.6 wt.\% Li). Figure 5(a) shows a TEM micrograph taken within a macroscopic shear band in Alloy B $(2.1 \mathrm{wt} . \% \mathrm{Li})$. The microstucture consists of small, $-500 \mathrm{~nm}$ grains formed by dynamic recrystallization. The insert (Figure 5(b)) is a SAD pattern consisting of sharp rings indicative of a microcrystalline structure. Figure $5(\mathrm{c})$ is a representative microdiffraction pattern taken from the small grains in the recrystallized region; the absence of superlattice reflections indicates that the precipitates were dissolved during shear band formation.

Figure 6a shows a TEM microgragh from Alloy C (2.6 wt.\% Li) through a grain-scale shear band adjacent to a larger macroscopic shear band such as that shown in Figure 4(a). The grain-scale shear band region has also undergone dynamic recrystallization producing a microcrystalline region. Figures 6(b) and 6(d) are microdiffraction patterns obtained from either side of the shear band showing the superlattice reflections indicative of the $\delta^{\prime}$ phase present surrounding the shear band. Figure 6(c) is a microdiffraction pattern taken from one of the small grains within the shear band, with superlattice reflections absent as a result of $\delta^{\prime}$ being dissolved by the heating of the shear band region. Every grains analyzed within this shear band was devoid of any $\delta^{\prime}$ as evident by the lack of superlattice reflections and an inability to image any precipitates. For alloys B, C, and D, all grains within either the macroscopic shear bands or the grain-scale shear bands were devoid of precipitates, indicating that the temperature rise in these shear bands were above the solvus temperature for each alloy. In the case of Alloy D, this solvus temperature is $318^{\circ} \mathrm{C}$. Similar analysis of the highest $\mathrm{Li}$ alloy (Alloy E) revealed recrystallized grains within the shear band (see Figure 7 (a), however in this cases the grains still contained $\delta^{\prime}$ precipitates as revealed by both superlattice reflections (see Figure $7(b)$ ) and precipitate images. The occurrence of recrystallization within each shear band can be expected since the recrystallization temperature is approximately $200^{\circ} \mathrm{C}$ for $\mathrm{Al}$. The presence of the precipitates indicates that the temperature rise did not exceed the solvus temperature of $335^{\circ} \mathrm{C}$. More interesting is the fact that the recrystallization occurred without disturbing the precipitate structure or the precipitate/matrix orientation relation.

Since the precipitates were absent in Alloy D (3.2 wt.\% Li), yet present in Alloy E (3.6 wt.\% Li) the temperature rise can be estimated to be between $\left(318^{\circ} \mathrm{C}\right.$ - Alloy D solvus temperature) and $\left(335^{\circ} \mathrm{C}\right.$ Alloy E solvus temperature). The dissolution was verified to be due to thermal effects only, by repeating a shear band experiment on Alloy $\mathrm{C}$, with the specimen held at $-200^{\circ} \mathrm{C}$. When this specimen was examined by TEM, the precipitates were still present, within the macroscopic shear band. However, the precipitates were absent in the grain-scale shear band indicating that the temperature rise in these finescale shear bands is significantly higher than in the macroscopic shear bands.

Figure 8 shows a bright-field/superlattice dark-field TEM micrograph pair from the shear band region in Alloy B ( $2.1 \mathrm{wt}$.\% Li) subjected to a shear strain of only 1 , showing the presence of precipitates. The microstructure shows partially recrystallized grain structure, yet the precipitates are essentially undisturbed. Since recrystallization is underway in this region, the mechanism of recrystallization involved, must be such that new grains are forming without the passage of a high angle grain boundary through the precipitates. If a high-angle grain boundary were to pass through the ordered structure of the precipitates, then the precipitates would be altered since a high-angle boundary is essentially a 

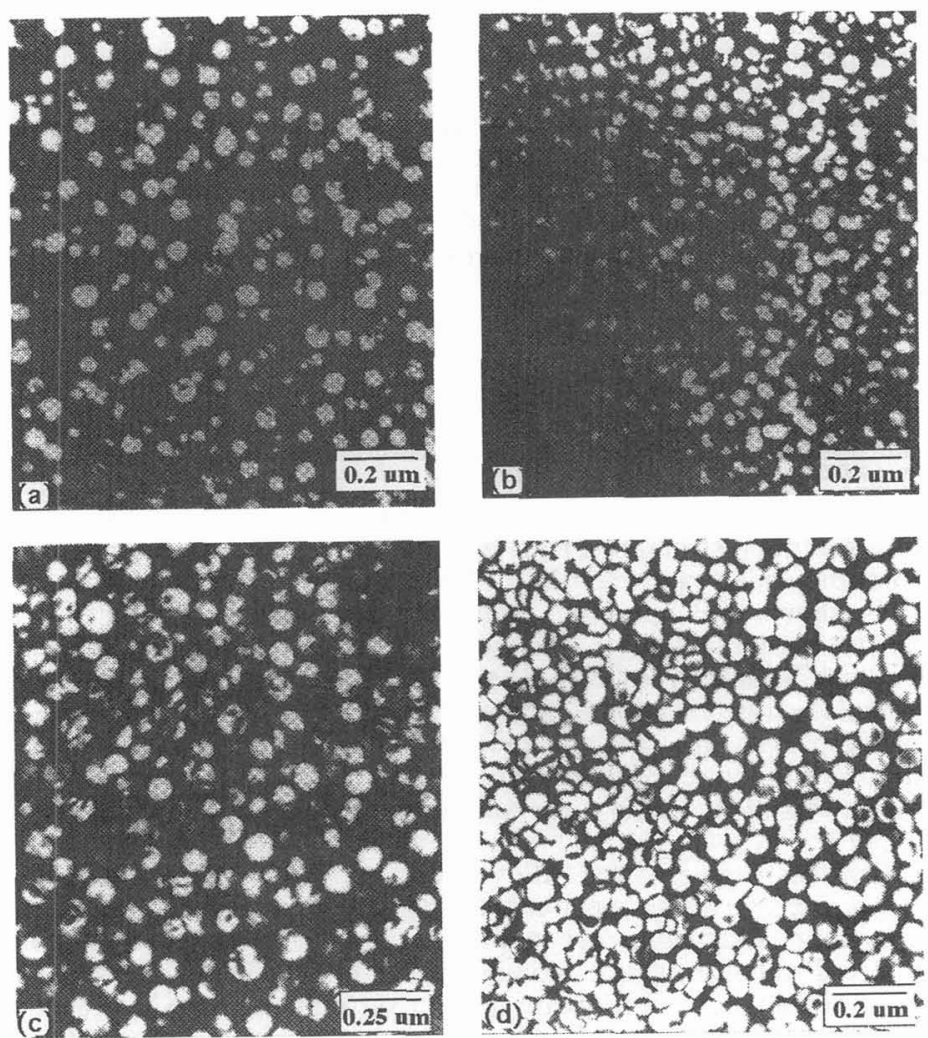

Figure 3. TEM dark-field micrographs using superlattice reflections showing the precipitate distributions for each alloy: (a) Alloy B [2.1 wt.\% Li], (b) Alloy C [2.6 wt.\% Li], (c) Alloy D [3.2 wt.\% Li], and (d) Alloy E [3.6 wt.\% Li].
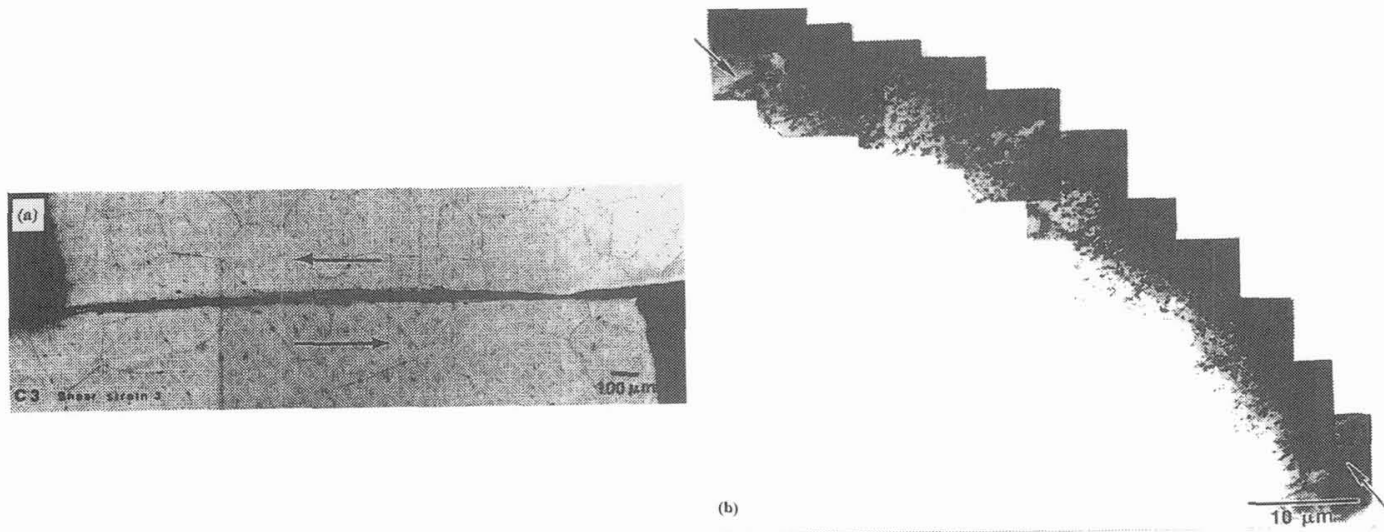

Figure 4. (a) Optical micrograph showing the shear band formed in Alloy $\mathrm{C}$ (2.6wt.\% Li) at high strain rate to a shear strain of $\sim 3$. (b) montage of TEM micrographs across the shear band formed in Alloy $E$ (higher magnification shown in Fig. 5). Arrows in (b) indicate edges of shear band. 


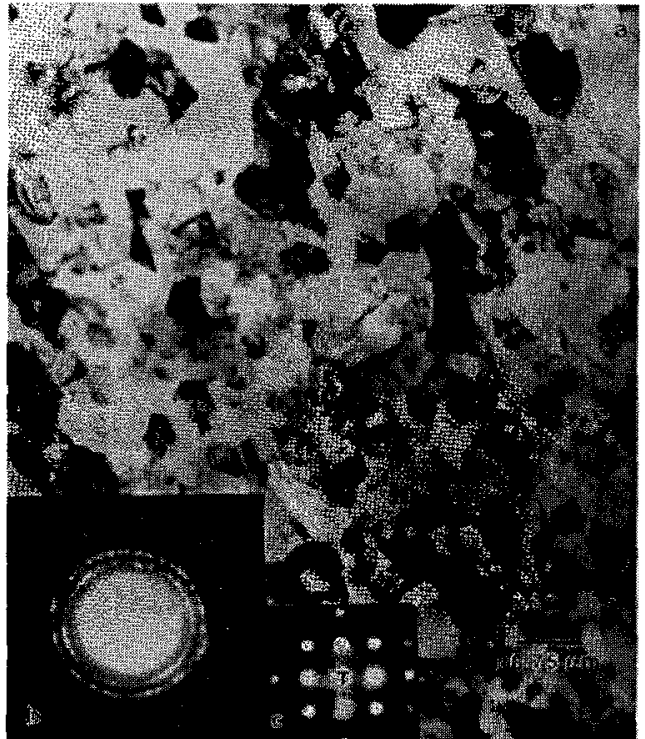

Figure 5. (a) TEM micrograph from Alloy B (2.1 structure in shear band, (b) shows SAD pattern consisting of sharp rings indicating microcrystalline structure, and (c) shows microdiffraction pattern from a small grain showing no superlattice reflections. Shear strain $=1$.

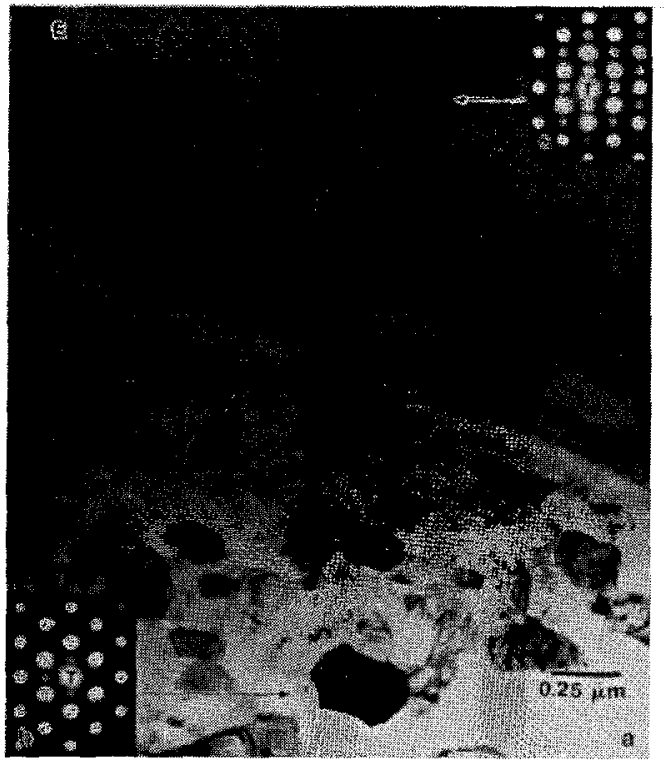
Figure 7. (a) TEM micrograph from Alloy E (3.6
wt.\% Li) showing recrystallized grains structure in shear band, (b) shows a microdiffraction pattern from a single small grain showing $\delta^{\prime}$ superlattice reflections, (c) microdiffraction pattern from matrix outside shear band showing superlattice reflections. Shear strain $=3$.

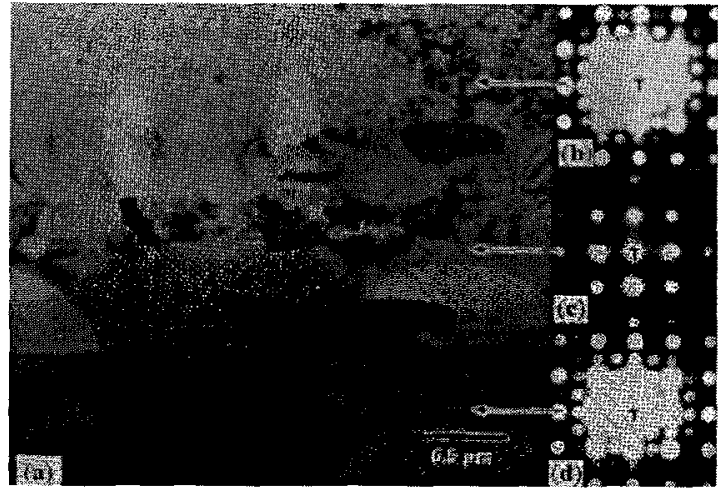

Figure 6. (a) TEM micrograph of grain-scale shear band in Alloy $\mathrm{C}$ ( 2.6 wt.\% Li) showing recrystallized grain structure. (b) and (d) microdiffraction patterns outside shear band containg superlattice reflections, (c) microdiffraction pattern from single grain in shear band showing no superlattice reflections. Shear strain $=3$.

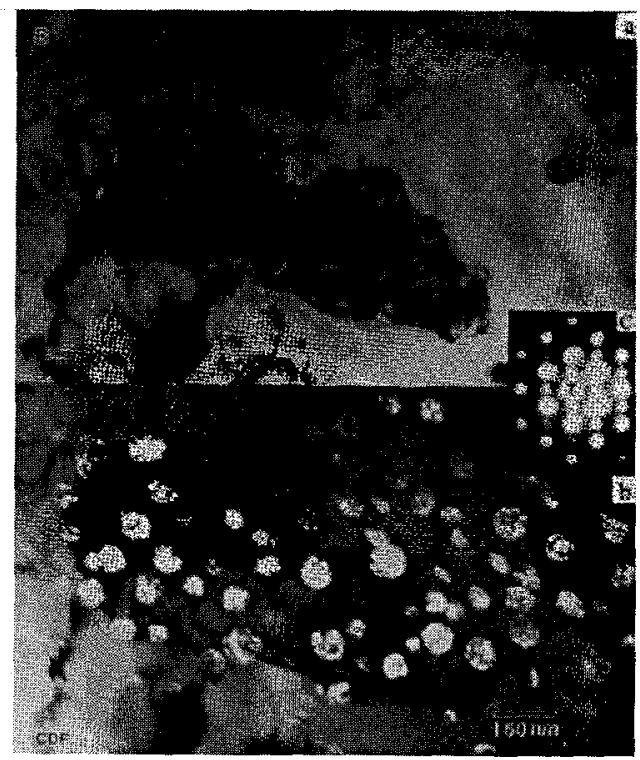

Figure 8. (a) Bright-field (b) superlattice dark-field TEM micrographs of shear band in Alloy B $(2.6 \mathrm{wt} . \% \mathrm{Li})$ showing recovered grain structure containing $\delta^{\prime}$ precipitates. (c) microdiffraction pattern from single grain in shear band showing superlattice reflections. Shear strain $=1$. 
disordered structure relative to the adjacent grain. As such, the dynamic recrystallization occuring in these shear bands must be occuring by the rotational mechanism, whereby new grains form from incremental rotation of dislocation cells until new high-angle grain boundaries are formed.

It is possible to estimate the dissolution kinetics associated with the shear-banding process by making a few simplifying assumptions. First, we can assume that the dissolution occurs during the time of deformation $(\sim 50 \mu \mathrm{s})$ and the cooling time of the shear region which has been estimated as $\sim 50 \mu \mathrm{s}$ from one-dimensional cooling calculations. Therefore the total time for dissolution is approximately $100 \mu s$. Second, we can assume that the kinetics for dissolution is at least as fast as for precipitation, and should be faster since there is no nucleation event associated with dissolution. The $\delta^{\prime}$ phase can form homogeneously upon quenching even when the quench rate approaches $10^{68} \mathrm{C} / \mathrm{s}$ as in rapid solidification processing. Since the temperature change in the shear band experiments is approximately $300^{\circ} \mathrm{C}$ and the time scale is $\sim 100 \mu \mathrm{s}$, the resulting heating rate is only $\sim 3 \times 10^{6 \times} \mathrm{C} / \mathrm{s}$. As such, the cooling rate to form $\delta^{\prime}$ and the heating rate to dissolve $\delta^{\prime}$ would be on the same order of magnitude. It is therefore reasonable to anticipate that complete $\delta^{\prime}$ dissolution is possible in the shear band experiments.

\section{SUMMARY AND CONCLUSIONS}

The temperature rise associated with shear band formation was investigated by using the variation in precipitate solvus temperature as a function of $\mathrm{Li}$ concentration to indirectly measure the temperature. The temperature rise was shown to be above the solvus temperature when precipitate dissolution occurred. For the alloys considered, this temperature rise was estimated to be close to $330^{\circ} \mathrm{C}$. When precipitates dissolution did not occur, yet recrystallization did occur, the precipitate structure and orientation relationship remained undisturbed. This result indicates that the mechanism of recrystallization that operates in these shear bands is of the rotational type, since the conventional nucleation and growth mechanism can not be postulated to leave the precipitate structure unchanged.

\section{ACKNOWLEDGMENTS}

The authors acknowledge the support of the National Science Foundation grant \# DMR-9110930 and the Army Research Office through a URI grant \# ARO-DAAL-03-92-G-0108 for this research.

\section{REFERENCES}

[1] D. B. Williams and J. W. Edington, 1975, Acta Metall., 35, 529.

[2] Meyer, L.W. and Manwarig, S., in "Metallurgical Applications of Shock-Wave and High-StrainRate Phenomena," M. Dekker, N.Y., 657, (1986).

[3] Nemat-Nasser, S., J. Isaacs, and J. E. Starrett, Proc. Roy. Soc., 435A, 371, (1991). 